\title{
Импульсное лазерное облучение светоизлучающих структур на основе GaAs
}

\author{
(C) О.В. Вихрова ${ }^{1}$, Ю.А. Данилов ${ }^{1}$, Б.Н. Звонков ${ }^{1}$, И.Л. Калентьева ${ }^{1}$, А.В. Нежданов ${ }^{2}$, \\ А.Е. Парафинн ${ }^{3}$, Д.В. Хомицкий ${ }^{2}$, И.Н. Антонов ${ }^{1}$ \\ ${ }^{1}$ Научно-исследовательский физико-технический институт \\ Нижегородского государственного университета им. Н.И. Лобачевского, \\ 603950 Нижний Новгород, Россия \\ ${ }^{2}$ Нижегородский государственный университет им. Н.И. Лобачевского, \\ 603950 Нижний Новгород, Россия \\ ${ }^{3}$ Институт ффизики микроструктур Российской академии наук, \\ 603950 Нижний Новгород, Россия \\ E-mail: vikhrova@nifti.unn.ru
}

Поступила в Редакцию 20 июля 2020 г.

В окончательной редакции 17 августа 2020 г.

Принята к публикации 17 августа 2020 г.

Исследованы эффекты воздействия импульсов эксимерного лазера $\mathrm{KrF}$ на кристаллические и оптические свойства структур с четырьмя квантовыми ямами $\mathrm{In}_{x} \mathrm{Ga}_{1-x} \mathrm{As} / \mathrm{GaAs}$ ( $x$ варьировалось от 0.08 до 0.25 ). Результаты, полученные методами спектроскопии комбинационного рассеяния света и спектроскопии отражения, показали, что высокое кристаллическое качество покровного слоя GaAs-структур сохраняется после воздействия лазерного излучения с плотностью энергии от 200 до 360 мДж/см². Экспериментально методом спектроскопии фотолюминесценции и посредством моделирования процесса лазерного отжига, представляющего собой решение задачи о распространении тепла в одномерной системе на основе GaAs, установлено, что термические воздействия, возникающие в гетероструктурах при импульсном лазерном облучении ниже порога плавления GaAs, приводят к релаксации механических напряжений, которая на начальных стадиях процесса обусловливает появление в квантовых ямах $\operatorname{In}_{x} \mathrm{Ga}_{1-x} \mathrm{As} / \mathrm{GaAs}$ точечных дефектов. Последние приводят к „красному“ сдвигу пиков фотолюминесцентного излучения квантовых ям и служат центрами безызлучательной рекомбинации, что вызывает гашение фотолюминесцентного излучения.

Ключевые слова: арсенид галлия, МОС-гидридная эпитаксия, гетеронаноструктура, импульсный лазерный отжиг.

DOI: 10.21883/FTP.2020.12.50234.9484

\section{1. Введение}

Локальное модифицирование электрических и оптических свойств квантово-размерных структур оптоэлектроники может производиться с помощью энергетических воздействий на них, в частности, ионно-имплантационного или импульсного лазерного облучения. Для светоизлучающих структур на основе GaAs ионная импланатация имеет два последствия, связанные с образованием радиационных дефектов. Во-первых, слой GaAs (или твердого раствора на его основе), где создаются радиационные точечные дефекты, после облучения некоторой пороговой дозой становится высокоомным [1], что позволяет электрически изолировать (локализовать) активные области квантово-размерных структур друг от друга на пластине. Во-вторых, присутствие избыточных (неравновесных) вакансий при условии проведения последующей термической обработки обеспечивает перемешивание состава материалов на границах раздела квантово-размерных структур с барьерами [2], что позволяет управлять оптическими параметрами структур (например, длиной волны люминесценции). В отличие от ионно-имплантационного перемешивания отжиг импульсами мощного лазерного излучения позволяет производить модифицирование структур в одну стадию без использования дополнительной термообработки [3]. Использование подходящей металлической маски дает возможность локально облучать лазером и изменять свойства выращенной структуры с целью, например, создания локальных областей, излучающих на нескольких длинах волн [4]. Использованию импульсного лазерного отжига для формирования оптоэлектронных схем мешает недостаток информации по изучению этого вопроса в литературе.

Цель настоящей работы - исследование эффектов воздействия импульсов эксимерного лазера на структуру и оптические свойства GaAs-гетероструктур с квантовыми ямами (КЯ) состава $\operatorname{In}_{x} \mathrm{Ga}_{1-x}$ As. В связи с этим необходимо отметить два обстоятельства. Во-первых, ранее влияние импульсного лазерного излучения на систему $\mathrm{GaAs} / \mathrm{InGaAs}$ не изучалось. Во-вторых, для исследования процессов проникновения теплового фронта в GaAs мы применили прием, ранее использованный в работе [5] для изучения распределения точечных дефектов в полупроводнике при ионной имплантации и анодном окислении: в использованных структурах на определенных 
расстояниях от поверхности располагались квантовые ямы $\operatorname{In}_{x} \mathrm{Ga}_{1-x} \mathrm{As}$, в которых варьировалось содержание индия. Поэтому спектр фотолюминесценции (ФЛ) такой структуры состоял из системы пиков, каждый из которых соответствовал определенной глубине залегания нанослоя квантовой ямы; полученный спектр ФЛ после воздействия на структуру давал полную информацию обо всех квантовых ямах и о глубине проникновения воздействия, которое приводило к гашению фотолюминесценции соответствующей КЯ.

\section{2. Методика эксперимента}

Для экспериментов были выращены структуры с квантовыми ямами $\mathrm{InGaAs} / \mathrm{GaAs}$ различного состава, используемыми для изготовления светоизлучающих структур [6]. Гетероструктуры формировались методом МОС-гидридной эпитаксии при атмосферном давлении. Подложки представляли собой пластины полуизолирующего GaAs (100). Вначале при температуре $650^{\circ} \mathrm{C}$ формировался буферный слой GaAs толщиной 0.3-0.4 мкм, затем при температуре $600^{\circ} \mathrm{C}$ выращивались последовательно четыре квантовые ямы InGaAs/GaAs (толщина слоя $\operatorname{In}_{x} \mathrm{Ga}_{1-x} \mathrm{As} \sim 10$ нм, толщина барьера $\mathrm{GaAs}-$ 50 нм), при этом содержание индия $(x)$ увеличивалось от 0.08 до 0.25 , а заканчивался процесс формированием покровного слоя $\mathrm{GaAs}$ толщиной $\sim 30$ нм. Схематическое изображение изготовленных гетероструктур представлено на рис. 1.

Образцы изготовленных структур подвергались воздействию расфокусированного пучка излучения им-

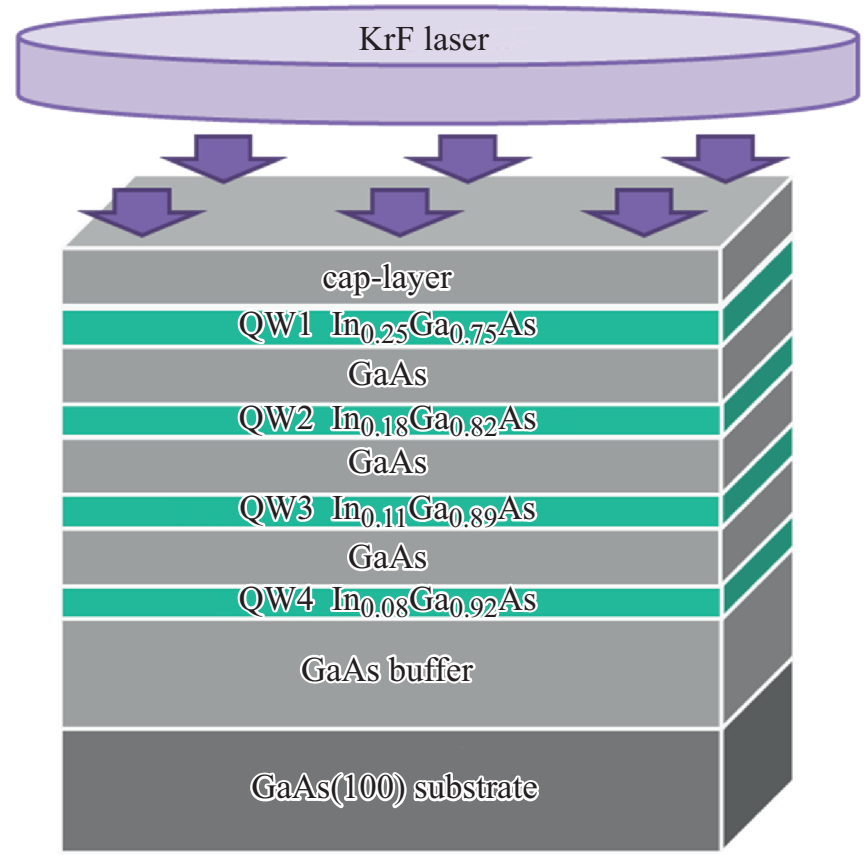

Рис. 1. Схематическое изображение исследованной структуры с квантовыми ямами $\mathrm{InGaAs} / \mathrm{GaAs}$ различного состава. пульсного эксимерного лазера LPX-200 (рабочая смесь $\mathrm{KrF}$, длина волны 248 нм, длительность импульса 30 нс). При этом плотность энергии варьировалась в диапазоне от 200 до 405 мДж/см².

Излучательные свойства исходных и отожженных лазером образцов исследовались методом измерения спектров фотолюминесценции при $77 \mathrm{~K}$. Для возбуждения спектров ФЛ использовался Не-Ne-лазер с длиной волны 632 нм мощностью $30 \mathrm{мBт}$.

Морфология поверхности образцов была изучена методом атомно-силовой микроскопии (АСМ) в атмосферных условиях с использованием сканирующей головки Smena на базе зондовой нанолаборатории NTEGRA Spectra компании NT-MDT (г. Зеленоград, Россия) в полуконтактном режиме с использованием зондов марки HA_NC. Шероховатость поверхности оценивалась стандартными программными методами с использованием программного обеспечения Gwyddion [7].

Спектры комбинационного рассеяния света (КРС) исследовались на комплексе NTEGRA Spectra производства NT-MDT с применением лазера с длиной волны 473 нм. Излучение фокусировалось $100 \times$ объективом с апертурой $\mathrm{NA}=0.9$. Мощность несфокусированного лазерного излучения, измеряемая с помощью кремниевого фотодетектора 11PD100-Si (Standa Ltd), составляла 0.5 мВт. Исследование спектров КРС проводились в геометрии обратного рассеяния. Измерения спектров КРС осуществлялись в диапазоне $50-900 \mathrm{~cm}^{-1}$ с разрешением $0.7 \mathrm{~cm}^{-1}$. Все спектры были получены при комнатной температуре. Время экспозиции составляло 120 с.

Спектральные зависимости коэффициента отражения были исследованы при комнатной температуре с помощью спектрофотометра Varian Cary 6000i в диапазоне энергий квантов света $1.5-4.5$ эВ с использованием приставки отражения под углом $12.5^{\circ}$.

\section{3. Результаты экспериментов}

Результаты исследования фотолюминесценции образцов структуры представлены на рис. 2. Спектр исходного образца (кривая O) состоит из пяти пиков. Пик ФЛ при энергии кванта 1.510 эВ соответствует межзонным переходам, вероятнее всего, в кристаллически совершенном и достаточно толстом буферном слое в GaAs. При меньших энергиях кванта расположены пики излучения квантовых ям QW4 (1.463 эB), QW3 (1.440 эВ), QW2 (1.358 эВ) и QW1 (1.280 эВ).

После лазерного отжига с минимальной используемой

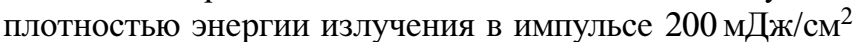
изменения происходят только в ближайших к поверхности квантовых ямах QW1 (центр ямы расположен от поверхности на глубине $\sim 35$ нм) и QW2 (глубина $\sim 95$ нм). Отмечено уменьшение интенсивности ФЛ от исходных значений на $25 \%$ в квантовой яме QW1 и на 9\% в квантовой яме QW2. Кроме того, наблюдается „красный“ сдвиг положения пика на 7 мэВ для КЯ QW1 


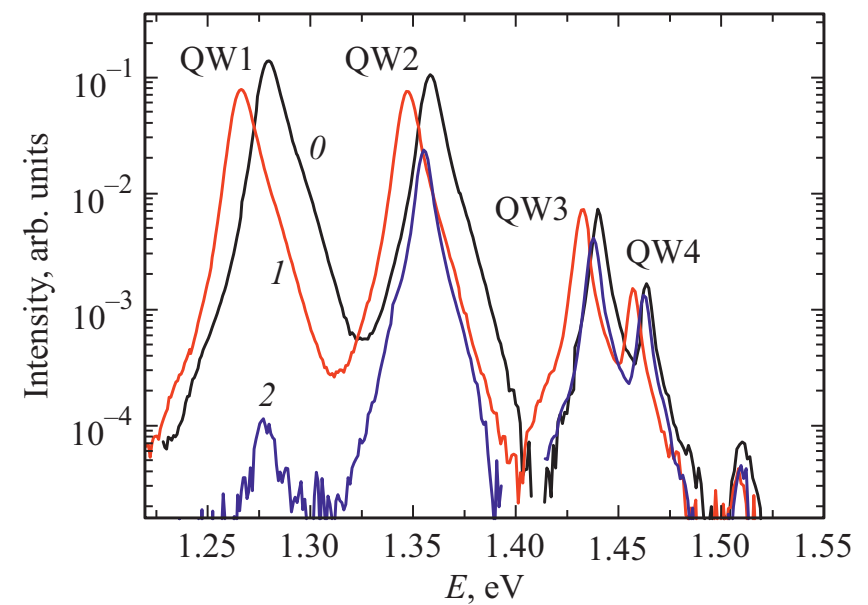

Рис. 2. Спектры фотолюминесценции при $77 \mathrm{~K}$ исходного $(0)$ и отожженных лазером образцов структуры с четырьмя квантовыми ямами с различным содержанием индия. Плотность

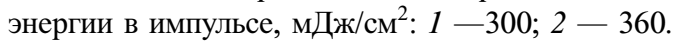

и на 4 мэВ в КЯ QW2. Третья (глубина $\sim 155$ нм) и четвертая (расстояние от поверхности $\sim 215$ нм) квантовые ямы практически не изменяют излучательных характеристик.

После воздействия на поверхность структуры импульса лазера с плотностью энергии 250 мДж/см² интенсивность излучения двух ближайших к поверхности квантовых ям продолжает уменьшаться (для QW1 интенсивность ФЛ снижается в 2.1 раза, а для QW2 - в 1.5 раза), и наблюдается дальнейшее „красное“ смещение пиков по сравнению со спектром фотолюминесценции исходного образца. Длинноволновый сдвиг увеличивается с возрастанием содержания индия и достигает 13 мэВ для квантовой ямы, расположенной у поверхности.

При увеличении плотности энергии в импульсе до величины $\sim 360$ мДж/см ${ }^{2}$ регистрируется гашение более чем на 3 порядка величины сигнала ФЛ квантовой ямы QW1, ближайшей к поверхности. Кроме того, наблюдается значительное уменьшение интенсивности фотолюминесценции для квантовых ям QW2 и QW3. Далее при плотности энергии 405 мДж/см² наблюдается полное гашение квантовых ям QW1 и QW2. Сигнал от квантовой ямы QW3 снижается почти на порядок величины, а излучение QW4 также значительно спадает.

Можно отметить также, что „красный“ сдвиг положения пиков от глубоко расположенных квантовых ям QW3 и QW4 наблюдается уже при плотностях энергии излучения 200-300 мДж/см², хотя изменений интенсивности при этом не происходит.

Исследование поверхности исходных и отожженных эксимерным лазером образцов структур методом атомно-силовой микроскопии не выявило никаких особенностей в морфологии. Отметим лишь некоторое увеличение шероховатости поверхности в результате лазерного отжига: для исходной структуры средне- квадратичная шероховатость $\left(S_{q}\right)$ составила $0.9 \mathrm{HM}$, а после отжига 111импульсом с плотностью энергии 360 мДж/ $/ \mathrm{cm}^{2} \sim 3 \mathrm{HM}$.

На рис. 3 показаны спектры КРС исходной и отожженных структур. Исследования методом КРС проводились в геометрии обратного рассеяния при выполнении правил отбора, запрещающих появление в спектре ТО-мод. Как видно из рис. 3, спектры исходного и отожженных лазером образцов практически совпадают и содержат интенсивный узкий пик в области LO-моды $\left(291.2 \mathrm{~cm}^{-1}\right)$ и слабо выраженный пик для ТО-моды $\left(267.4 \mathrm{~cm}^{-1}\right)$. Присутствие ТО-моды связано с небольшими нарушениями геометрии обратного рассеяния света и (или) отклонением ориентации пластины от плоскости (100). Положение TO- и LO-мод в пределах погрешности измерения соответствует их положению в монокристаллическом GaAs. Полная ширина на полувысоте для пика, соответствующего продольной оптической моде, в случае исходного образца составляет не более $4 \mathrm{~cm}^{-1}$ и не изменяется после лазерного воздействия. Полученные данные позволяют заключить, что покровный слой квантово-размерной структуры имеет высокое кристаллическое качество, и оно не ухудшается после воздействия лазерного излучения с плотностью энергии в импульсе от 200 до 360 мДж/ $\mathrm{cm}^{2}$.

На рис. 4 приведены спектры оптического отражения исследованных структур до и после обработки импульсом эксимерного лазера. Спектр отражения поверхности исходного образца (спектр 0 на рис. 4) содержит характерный для монокристаллического GaAs дублет пиков в области энергий $E_{1}(2.9$ эВ $)$ и $E_{1}+\Delta_{1}(3.12$ эВ $)$, соответствующий переходам в направлении $\Lambda$ зоны Бриллюэна [8]. Для образцов, обработанных лазерным излучением с плотностью энергии в импульсе до 300 мДж/см²,

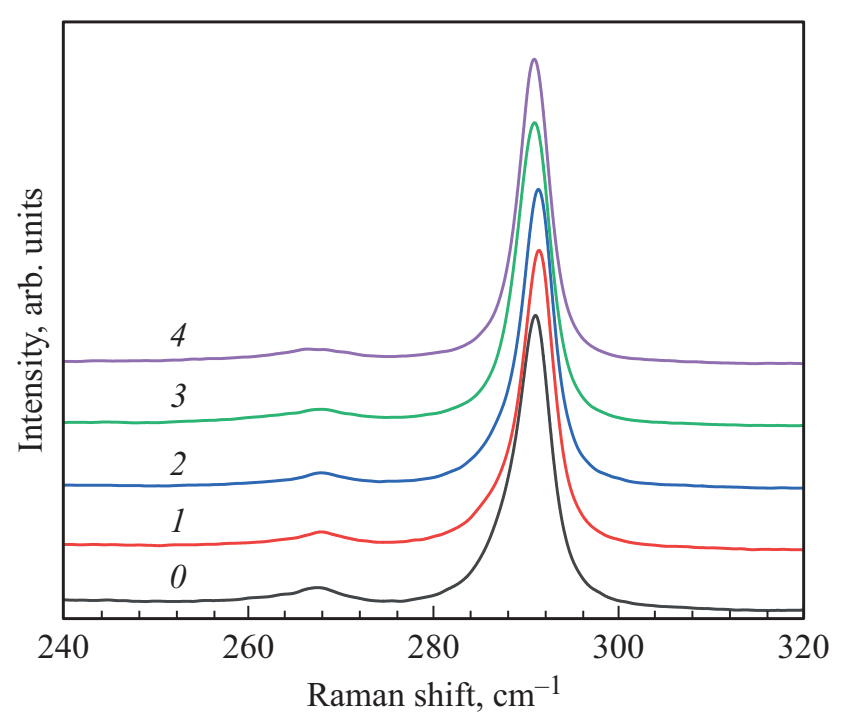

Рис. 3. Спектры КРС при $300 \mathrm{~K}$ для исходного $(0)$ и отожженных лазером образцов структуры с четырьмя квантовыми ямами с различным содержанием индия. Плотность энергии в импульсе, мДж/см² $1-200,2-250,3-300$ и $4-360$. 


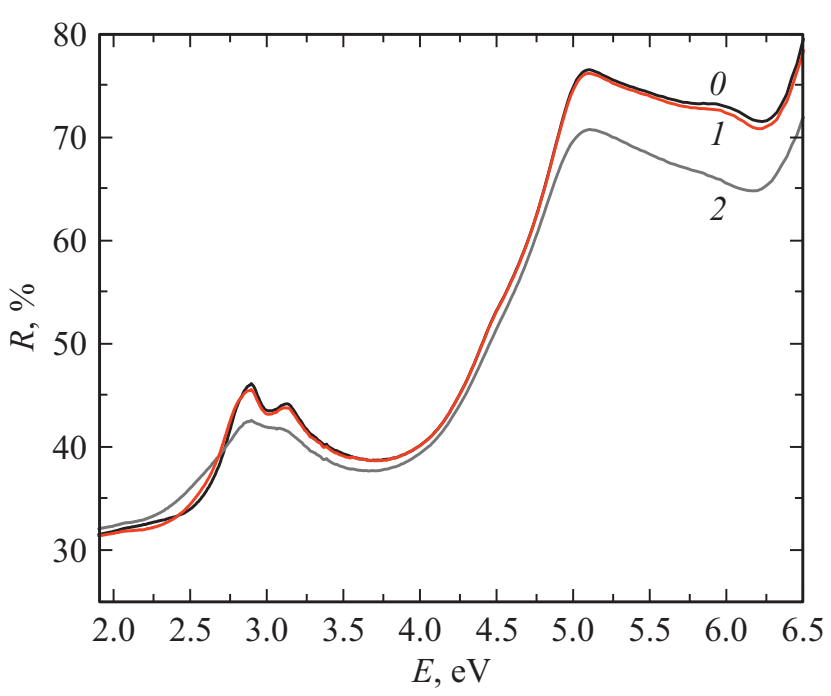

Pис. 4. Спектры оптического отражения поверхности структур: $O$ - исходная структура; после облучения импульсом лазера с плотностью энергии 300 (1) и 405 (2) мДж/см².

спектр отражения практически не изменяется (спектр 1 на рис. 4). В случае плотности энергии $405 \mathrm{mДж/ \textrm {cm } ^ { 2 }}$ (спектр 2 на рис. 4) дуплет размывается и коэффициент отражения заметно уменьшается, что свидетельствует об ухудшении кристаллического качества покровного слоя GaAs. Можно предположить, что при такой плотности энергии импульса эксимерного лазера происходит нарушение стехиометрии арсенид-галлиевого покровного слоя вследствие частичного испарения мышьяка и образование окислов галлия на поверхности структуры, поскольку процесс лазерного отжига осуществлялся на открытом воздухе. Об изменениях морфологии покровного слоя (увеличение шероховатости) после отжига при

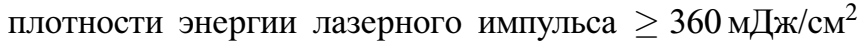
свидетельствуют и данные атомно-силовой микроскопии (см. выше).

В целом можно полагать, что основной вклад в эффекты, наблюдаемые в результате лазерного отжига (в первую очередь в спектрах ФЛ), вносят тепловые воздействия на структуры. С целью проверки этого предположения предпринят расчет термических процессов, происходящих в полупроводнике типа $\mathrm{GaAs}$ при импульсном лазерном отжиге.

\section{4. Моделирование процесса лазерного отжига}

Была решена задача о распространении тепла в одномерной системе на основе GaAs. Не вдаваясь в микроскопические механизмы превращения энергии, считаем, что поглощенная энергия лазерного излучения полностью переходит в тепловую энергию. Итак, тепло происходит от поглощения полупроводником лазерного импульса $f(x, t)$, падающего на левый край образца $(x=0)$ и эффективно поглощаемого до глубины $l$ по закону $\exp (-x / l)$. Параметр $l=1 / \alpha$, где $\alpha-$ коэффициент поглощения на длине волны излучения лазера (для эксимерного KrF-лазера $\lambda=248$ нм). Величина $l$ оценивается для GaAs по разным источникам $[9,10]$ в 5-10 нм. При расчетах были использованы данные из более позднего источника [10] с $l=10$ нм, хотя на конечный результат эти изменения влияют мало.

Полагаем, что зависимость интенсивности лазерного импульса от времени имеет гауссов профиль с характерной полушириной $\Delta t=15$ нс. Моделирование распространения тепла начинается с момента, предшествующего максимуму импульса на величину $2 \Delta t=30 \mathrm{нc}$. Еще через 15 нс импульс эффективно заканчивается. После этого задача моделируется в течение $55 \mathrm{Hc}$, так что общее время моделирования составляет $100 \mathrm{Hc}$. Результаты показывают, что максимальный нагрев достигается почти сразу после прохождения максимума импульса, и в дальнейшем с течением времени температура снижается вследствие распространения тепла в глубь подложки и теплопередачи вовне от края $x=0$, поэтому такой промежуток времени представляется достаточным.

Известно, что падающий на поверхность поток излучения должен быть умножен на величину $(1-R)$, чтобы получить интенсивность излучения, входящего в полупроводниковую среду [11]. Здесь $R-$ коэффициент отражения на границе полупроводника с воздухом. Для расчета выберем $R=0.75$ (это значение хорошо согласуется с $R$ для исходной структуры - рис. 4), тогда величина $(1-R)=0.25$.

Распространение тепла в системе, для которой перепады температур столь значительны, что коэффициент теплопроводности зависит от температуры, может описываться квазилинейным уравнением теплопроводности для распределения температуры $u=u(x, t)$ [12]:

$$
c(u) \frac{\partial u}{\partial t}=\frac{\partial}{\partial x}\left(k(u) \frac{\partial u}{\partial x}\right)+f(x, t) .
$$

Источник тепла в виде лазерного импульса описывается выражением

$$
f(x, t)=f_{0} \cdot \exp \left(-\frac{x}{l}\right) \cdot \frac{1}{\sqrt{2 \pi \Delta_{t}^{2}}} \exp \left(-\frac{\left(t-t_{0}\right)^{2}}{2 \Delta_{t}^{2}}\right),
$$

где выбранный начальный момент времени, отстоящий от максимума импульса на $t_{0}=2 \Delta t$, и величина дисперсии $\Delta_{t}^{2}=(\Delta t)^{2}$ определяются полушириной профиля энергии импульса по времени.

В уравнении (1) как коэффициент теплопроводности $k(u)$, так и теплоемкость $c(u)$ являются функциями температуры. Представленные в работе [10] данные для этих температурных зависимостей были аппроксимированы 
простыми выражениями вида

$$
k(u)=\frac{k\left(u_{0}\right)}{1+\gamma\left(u-u_{0}\right)}, \quad c(u)=c\left(u_{0}\right)+\delta\left(u-u_{0}\right),
$$

а параметры в аппроксимациях (3) подобраны для наилучшего согласования с представленными табличными данными.

Граничные условия для уравнения (1) были выбраны следующим образом. Для учета теплопередачи на краю $x=0$ используется граничное условие третьего рода [12]

$$
k \frac{\partial u}{\partial x}=\beta\left(u-\theta_{0}\right)
$$

описывающее теплообмен с внешней средой, имеющей постоянную температуру $\theta_{0}$. Следует отметить, что справочные данные для параметра теплообмена $\beta$ между арсенидом галлия и воздухом практически отсутствуют. Однако известно, что для тведых тел, обменивающихся теплом с воздухом, коэффициент теплопередачи находится в диапазоне от нескольких единиц до нескольких тысяч Дж/( $\left.\mathrm{m}^{2} \cdot \mathrm{K}\right)$. Это означает, согласно (4), что с одного квадратного сантиметра поглощенная энергия лазерного импульса, равная $\sim 0.5$ Дж/ $\mathrm{cm}^{2}$, будет излучаться в пространство в течение времени от 0.01 до нескольких секунд. Известно, однако, что в случае наносекундных импульсов лазерного излучения процесс нагрева приповерхностного слоя протекает значительно быстрее, в течение $\sim 100$ нс. В этом смысле практическое применение условия (4) можно осуществлять с любым подходящим по классу материалов коэффициентом $\beta$, так как эффективно на интервале времени от 0 до 100 нс образец является теплоизолированным, т.е. работает предел $\beta \rightarrow 0$. Аналогичное граничное условие можно применить и на правой границе области моделирования, расположенной на глубине $d=2000$ нм. Тепловые потоки в рамках условия (4) на этой глубине являются незначительными по сравнению с распространением тепла в рамках самого уравнения (1).

Начальным условием в нашей задаче является постоянная температура вдоль всей структуры, равная комнатной:

$$
u(x, 0)=\theta_{0}
$$

Краевая задача математической физики, заданная выражениями $(1)-(5)$, допускает только численное решение. Для решения квазилинейных уравнений вида (1) разработаны методы конечных разностей, включающие неявную схему, применяемую с использованием метода прогонки [12]. Мы выполняли моделирование задачи на сетке, содержащей 20000 точек в пространственном интервале от 0 до 2000 нм и 2000 точек во временно́м интервале от 0 до 100 наносекунд. Для процессов, генерируемых импульсом длительностью 30 нс и протекающих в слое толщины 100 нм, указанный размер сетки представляется оптимальным. Дальнейший рост числа узлов сетки, как показало настоящее моделирование, существенно не влияет на точность основного результата о прогреве приповерхностного слоя толщиной 100 нм.
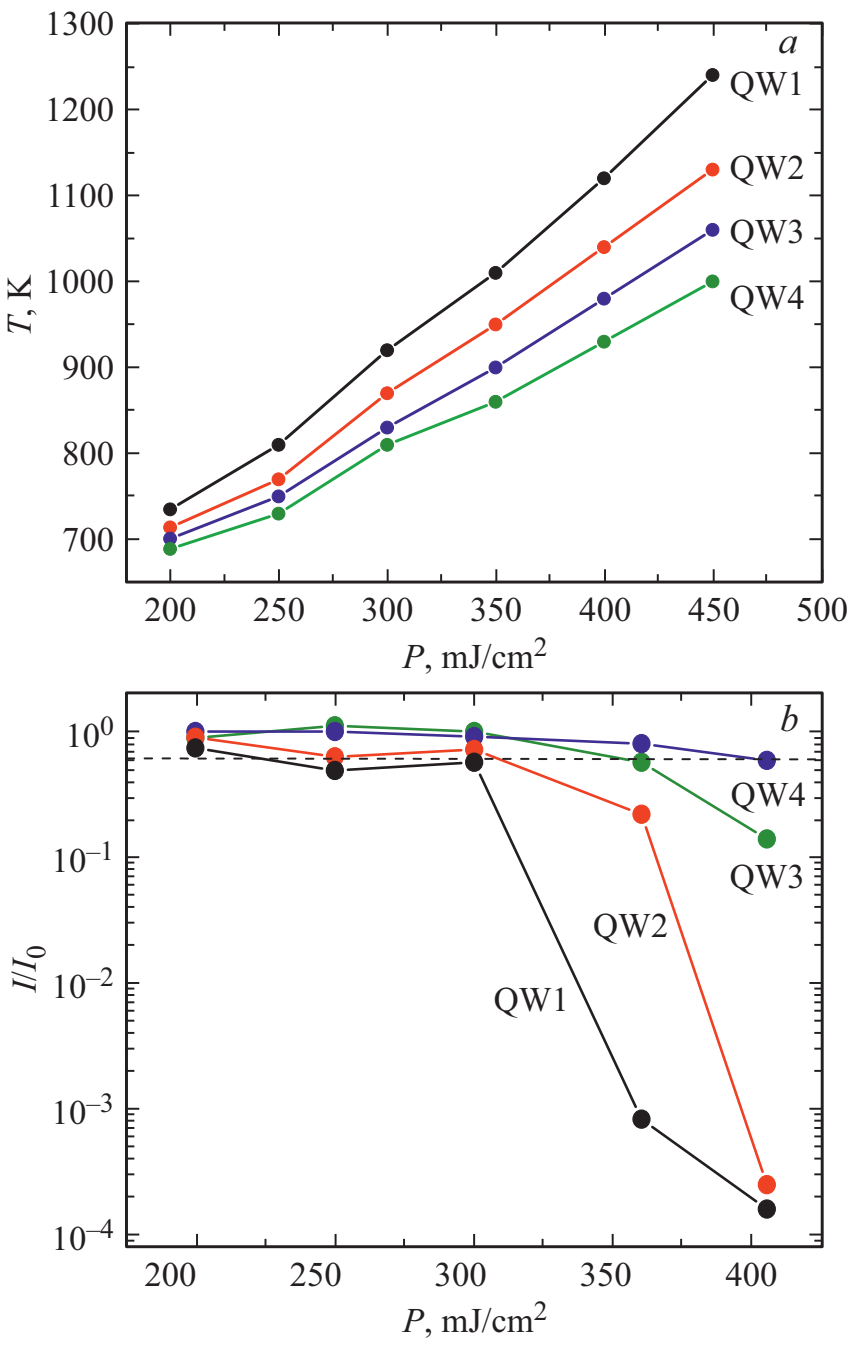

Рис. 5. $a-$ расчетная зависимость максимальной температуры в области расположения каждой из четырех квантовых ям при различных плотностях энергии импульса лазерного излучения; $b-$ экспериментальная зависимость гашения интенсивности фотолюминесценции (отношение интенсивности пика ФЛ к исходному значению $\left.I_{0}\right)$ при варьировании плотности энергии для квантовых ям QW1, QW2, расположенных вблизи поверхности структуры, и для КЯ QW3, QW4.

Результаты моделирования позволяют сделать вывод о том, что температура плавления арсенида галлия, равная $1530 \mathrm{~K}$, может быть достигнута в приповерхностном слое GaAs толщиной 100 нм при использовании плотности энергии излучения $P \sim 640$ мДж/см ${ }^{2}$. В наших экспериментах использовались более низкие плотности энергии лазера, поэтому плавления $\mathrm{GaAs}$ не происходило.

Из расчетов можно видеть, что максимальная температура достигается в приповерхностном слое вскоре после прохождения максимума лазерного импульса и постепенно спадает во времени, а также в глубь подложки.

В рамках предложенной модели рассчитано распределение температуры по глубине структуры в различные 
моменты времени. Максимальная температура, достигаемая на глубинах, соответствующих положению всех четырех квантовых ям GaAs, показана на рис. 5, $a$ и представляет собой монотонно возрастающую величину на зависимости от плотности энергии лазерного импульса.

\section{5. Обсуждение результатов}

Есть смысл обсудить,- в первую очередь, механизм уменьшения интенсивности излучения квантовых ям при воздействии лазерного импульса.

Рассмотрим возможность размытия квантовых ям за счет взаимной твердотельной диффузии атомов In и $\mathrm{Ga}$ на границе раздела „квантовая яма InGaAs/GaAs барьер“ в течение лазерного импульса. Примем, что высокотемпературное состояние в области границы раздела (пока безотносительно к номеру квантовой ямы) имеет эффективную длительность $t_{\text {eff }} \sim 100$ нс. Известна температурная зависимость коэффициента взаимной диффузии [13]

$$
D_{\text {In-Ga }}=5.1 \cdot 10^{-12} \exp \left(-1.08 / k_{\mathrm{B}} T\right)\left[\mathrm{cm}^{2} / \mathrm{c}\right] .
$$

В этой формуле энергия активации выражена в эВ, $k_{\mathrm{B}}$ - постоянная Больцмана, $T$ - абсолютная температура. При $1500 \mathrm{~K}$ (т.е. при температуре, близкой к температуре плавления GaAs) значение $D_{\text {In-Ga }}$ coставляет $1.2 \cdot 10^{-15} \mathrm{~cm}^{2} / \mathrm{c}$, тогда оценка диффузионной длины $\left(D_{\mathrm{In}-\mathrm{Ga}} \cdot t_{\mathrm{eff}}\right)^{1 / 2}$ дает значение $\sim 10^{-11} \mathrm{~cm}$, которое не имеет физического смысла и никак не объясняет размытие квантовой ямы за счет взаимной диффузии компонентов материала гетероструктуры. Практически точно такое же значение диффузионной длины взаимной диффузии $\mathrm{In}-\mathrm{Ga}\left(1.1 \cdot 10^{-11} \mathrm{~cm}\right)$ дают расчеты для той же температуры $1500 \mathrm{~K}$ с использованием формулы, предложенной в [14]:

$$
D_{\text {In-Ga }}=4.0 \cdot 10^{-9} \exp \left(-1.93 / k_{\mathrm{B}} T\right)\left[\mathrm{cm}^{2} / \mathrm{c}\right] .
$$

В связи с этим рассмотрим другие вероятные причины уменьшения интенсивности излучения квантовых ям в результате импульсного лазерного отжига. Таковыми могут быть, на наш взгляд: $(a)$ сегрегация индия, происходящая после окончания лазерного импульса при охлаждении структуры; (б) релаксация напряжений на границе раздела „квантовая яма InGaAs/GaAs барьер“; (в) жидкофазное перемешивание материалов квантовой ямы и барьеров [15].

Существенный вклад в наблюдаемые эффекты (в первую очередь в уменьшение интенсивности ФЛ квантовых ям) сегрегация индия (механизм $(a))$ внести не могла, так как, если бы это явление произошло, тонкий поверхностный слой GaAs был бы обогащен индием, что должно было сказаться на спектре КРС. Коэффициент поглощения GaAs на длине волны 473 нм составляет $\sim 2 \cdot 10^{-5} \mathrm{~cm}^{-1}[16]$. Следовательно, поглощение возбуждающего КРС лазерного излучения происходит в основном в слое толщиной $\sim 50$ нм, т.е. в покровном $\mathrm{GaAs}$ слое и немного захватывает QW1. Появление „хвоста“ распределения атомов индия в покровном слое при сегрегационных явлениях в InGaAs/GaAs-гетероструктурах отмечалось ранее [17], но в данной работе не наблюдается.

Согласно нашим расчетам (см. выше), температура плавления при использованных плотностях энергии импульса лазерного излучения не достигается. Здесь можно рассмотреть снижение температуры плавления материала квантовой ямы по сравнению с $T_{m}$ для GaAs. Оценка с использованием линейного правила Вегарда дает снижение $T_{m}$ лишь на $74 \mathrm{~K}$ для $\operatorname{In}_{x} \mathrm{Ga}_{1-x}$ As c $x=0.25$. Эта разница не может привести к селективности плавления в исследуемой гетероструктуре. Поэтому механизм $(b)$ также не рассматривается в качестве вносящего вклад в наблюдаемое явление.

В связи с вышесказанным полагаем, что снижение интенсивности излучения квантовых ям в результате воздействия импульсного лазерного излучения происходит вследствие релаксации напряжений на границе раздела „квантовая яма InGaAs/GaAs барьер“. Существенное отличие исследованных в данной работе структур от большинства литературных данных по импульсному лазерному отжигу квантово-размерных структур состоит в том, что квантовые ямы InGaAs являются напряженными. Если по какой-то причине происходит релаксация механических напряжений, то на границах раздела InGaAs/GaAs создаются дислокации несоответствия, что приводит к появлению центров безызлучательной рекомбинации для фотогенерированных при измерениях носителей и к соответствующему уменьшению интенсивности ФЛ.

Рассмотрим зависимость относительной интенсивности фотолюминесценции квантовых ям от плотности энергии лазерного импульса. Для исследованных структур эта зависимость приведена на рис. 5, $b$. Используя рис. 5, $a$ и $b$, мы можем сделать оценку, какой расчетной температуре $T_{q}$ соответствует гашение фотолюминесцентного излучения, например, до уровня $0.6 \cdot I_{0}$. Для четырех квантовых ям получены значения $T_{q} 780 \mathrm{~K}$ (QW1), $810 \mathrm{~K}$ (QW2), $920 \mathrm{~K}$ (QW3) и $930 \mathrm{~K}$ (QW4). С одной стороны, тенденция вполне разумная: чем больше содержание индия в квантовой яме, тем меньшая температура требуется для релаксации напряжений в ней. С другой стороны, полученные температуры меньше или близки к температуре выращивания структур $\left(600^{\circ} \mathrm{C}\right)$, поэтому нельзя полагать, что релаксация напряжений в квантовых ямах в процессе лазерного облучения - результат только температурного воздействия. Известны температуры термического отжига, при которых происходит релаксация механических напряжений квантовых ям $\operatorname{In}_{x} \mathrm{Ga}_{1-x} \mathrm{As} / \mathrm{GaAs}$ с величиной $x=0.09-0.15$; она зависит от толщины слоя InGaAs и обычно находится в диапазоне $700-775^{\circ} \mathrm{C}$ [18-20].

Специфика процессов, происходящих при импульсном лазерном воздействии на твердые тела, заключается не 
только в кратковременном нагреве, но и в том, что вследствие градиента температуры (расширение верхнего слоя, поглощающего излучение) в пластине возникают механические напряжения [21], которые могут при превышении пределов упругости материала привести к пластической деформации. Это явление более характерно для металлов (наблюдалось в алюминии даже при плотностях энергии лазерного импульса ниже порога плавления [21]), но также, на наш взгляд, может происходить и в напряженных полупроводниковых гетероструктурах.

Отметим также, что начальные стадии формирования дислокаций несоответствия в напряженных квантовых ямах InGaAs/GaAs наблюдались даже при не очень высоких температурах термического отжига $\left(\sim 500^{\circ} \mathrm{C}\right)[18]$. Сообщалось также, что на первых стадиях процесса релаксации напряжений (до формирования дислокаций) образуются точечные дефекты, которые и являются центрами безызлучательной рекомбинации в квантовых ямах [22].

Требует объяснения и небольшой „красный“ сдвиг пиков фотолюминесценции квантовых ям после импульсного лазерного облучения. Он также может быть связан с появлением в квантовых ямах точечных дефектов. „Красный“ сдвиг пиков ФЛ (наряду с гашением) в облученных быстрыми нейтронами напряженных гетероструктурах InGaAs/GaAs наблюдался в [23]. Очевидно, что при этом в структуру вводились лишь точечные дефекты. Напротив, при перемешивании на границе раздела в структурах $\mathrm{InGaAs} / \mathrm{GaAs}$ за счет взаимной диффузии In-Ga при термических обработках всегда наблюдается „синий“ сдвиг (см., например, работу [24]).

Таким образом, термические воздействия, возникающие в гетероструктурах с напряженными квантовыми ямами $\mathrm{InGaAs} / \mathrm{GaAs}$ при импульсном лазерном облучении ниже порога плавления GaAs, приводят к релаксации механических напряжений, которая на начальных стадиях процесса обусловливает появление в квантовых ямах точечных дефектов. Последние приводят к „красному“ сдвигу пиков ФЛ КЯ (увеличению длины волны излучения квантовых ям) и служат центрами безызлучательной рекомбинации, что вызывает гашение фотолюминесцентного излучения.

\section{6. Заключение}

В работе впервые проведено исследование эффектов воздействия импульсов эксимерного лазера на структуру и оптические свойства гетероструктур с напряженными квантовыми ямами InGaAs/GaAs. Для исследования процессов проникновения теплового фронта в GaAs был применен прием, когда в структурах на определенных расстояниях от поверхности располагались квантовые ямы InGaAs/GaAs c различным содержанием индия. Поэтому спектр фотолюминесценции такой структуры, состоящий из системы пиков, каждый из которых соответствовал определенной глубине залегания нанослоя квантовой ямы, после лазерного воздействия на структуру давал полную информацию обо всех квантовых ямах и о глубине проникновения воздействия.

В результате проведенных исследований было обнаружено гашение люминесцентного излучения и уменьшение энергии основного перехода квантовых ям с увеличением плотности энергии лазерного импульса от 200 до 405 мДж/см². Исследования атомно-силовой микроскопии выявили небольшое увеличение шероховатости поверхности структур в результате лазерного отжига. Полученные данные спектроскопии комбинационного рассеяния света и спектроскопии отражения позволяют заключить, что покровный слой квантоворазмерной структуры имеет высокое кристаллическое качество и оно не ухудшается после воздействия лазерного излучения с плотностью энергии в импульсе от 200 до 360 мДж/см². Экспериментально по результатам спектроскопии фотолюминесценции и посредством моделирования процесса, представляющего собой решение задачи о распространении тепла в одномерной системе на основе GaAs, установлено, что основной вклад в эффекты, наблюдаемые в результате лазерного отжига (в первую очередь в спектрах фотолюминесценции), вносят тепловые воздействия на структуры. В рамках предложенной модели рассчитано распределение температуры по глубине структуры в различные моменты времени.

Проанализированы наиболее вероятные причины уменьшения интенсивности фотолюминесцентного излучения квантовых ям в результате импульсного лазерного отжига: $(a)$ сегрегация индия, происходящая после окончания лазерного импульса при охлаждении структуры; (б) релаксация напряжений на границе раздела „Квантовая яма InGaAs/GaAs барьер“; (в) жидкофазное перемешивание материалов квантовой ямы и барьеров. Показано, что снижение интенсивности излучения квантовых ям в результате воздействия импульсного лазерного излучения происходит вследствие релаксации напряжений на границе раздела „квантовая яма $\mathrm{InGaAs} / \mathrm{GaAs}$ барьер“. При релаксации механических напряжений создаются дислокации несоответствия, а на начальных стадиях процесса формирования дислокаций в квантовых ямах появляются точечные дефекты, которые приводят к длинноволновому смещению пиков фотолюминесценции квантовых ям и служат центрами безызлучательной рекомбинации, что вызывает уменьшение интенсивности фотолюминесценции.

\section{Финансирование работы}

Работа выполнена при поддержке Российского научного фонда (грант № 19-19-00545).

\section{Конфликт интересов}

Авторы заявляют, что у них нет конфликта интересов. 


\section{Список литературы}

[1] I. Danilov, L.L. Pataro, M.P.P. de Castro, N.C. Frateschi. J. Appl. Phys., 88, 7354 (2000).

[2] D.G. Deppe, N. Holonyak, jr. J. Appl. Phys., 64, R93 (1988).

[3] R. Beal, V. Aimez, J.J. Dubowski. Opt. Express, 23, 1073 (2015).

[4] J. Dubowski, X.R. Zhang, X. Xu, J. Lefebvre, Z. Wasilewski. Proc. SPIE, 5339, 93 (2004).

[5] И.А. Карпович, А.В. Аншон, Н.В. Байдусь, Л.М. Батукова, Ю.А. Данилов, Б.Н. Звонков, С.М. Планкина. ФТП, 28, 104 (1994).

[6] Н.В. Дикарева, Б.Н. Звонков, И.В. Самарцев, С.М. Некоркин, Н.В. Байдусь, А.А. Дубинов. ФТП, 53, 1718 (2019).

[7] D. Nečas, P. Klapetek. Cent. Eur. J. Phys., 10, 181 (2012).

[8] Ю.И. Уханов. Оптические свойства полупроводников (М., Наука, 1977) с. 139.

[9] В.И. Гавриленко, А.М. Грехов, Д.В. Корбутяк, В.Г. Литовченко. Оптические свойства полупроводников (Киев, Наук. думка, 1987) с. 207.

[10] T. Kim, M.R. Pillai, M.J. Aziz, M.A. Scarpulla, O.D. Dubon, K.M. Yu, J.W. Beeman, M.C. Ridgway. J. Appl. Phys., 108, N 013508 (2010).

[11] P. Baeri, S.U. Campisano. Laser Annealing in Semiconductors, ed. by J.M. Poate, J.W. Mayer (N. Y., Academic Press, 1982) p. 75.

[12] А.Н. Тихонов, А.А. Самарский. Уравнения математической ббизики (М., Наука, 1977).

[13] Н.А. Берт, Ю.Г. Мусихин, В.В. Преображенский, М.А. Путято, Б.Р. Семягин, А.А. Суворова, В.В. Чалдышев, P. Werner. ФТП, 32, 769 (1998).

[14] J.S. Tsang, C.P. Lee, S.H. Lee, K.L. Tsai, J.C. Fan. J. Appl. Phys., 79, 664 (1996).

[15] J. Ralston, A.L. Moretti, R.K. Jain, F.A. Chambers. Appl. Phys. Lett., 50, 1817 (1987).

[16] J.S. Blakemore. J. Appl. Phys., 53, R123 (1982).

[17] Ю.Н. Дроздов, Н.В. Байдусь, Б.Н. Звонков, М.Н. Дроздов, О.И. Хрыкин, В.И. Шашкин. ФТП, 37, 203 (2003).

[18] J. Kui, W.A. Jesser. J. Electron. Mater., 20, 827 (1991).

[19] M.A. Lourenco, K.P. Homewood, L. Considine. Mater. Sci. Eng. B, 28, 507 (1994).

[20] B. Sarikavak, M.K. Ozturk, T.S. Mammadov, S. Ozcelik. Cryst. Res. Technol., 45, 517 (2010).

[21] Д.М. Поут, Г. Фоти, Д.К. Джекобсон. Модифицирование и легирование поверхности лазерными, ионными и электронными пучками (М., Машиностроение, 1987) c. 424.

[22] N.V. Vostokov, D.M. Gaponova, V.M. Daniltsev, Yu.N. Drozdov, O.I. Khrykin, A.V. Murel, V.I. Shashkin, I.Yu. Shuleshova. Phys. Low-Dim. Structur., 3, 303 (2001).

[23] Н.В. Байдусь, О.В. Вихрова, Б.Н. Звонков, Е.И. Малышева, А.Н. Труфанов. ФТП, 49, 370 (2015).

[24] Y.M. Park, Y.J. Park, K.M. Kim, J.D. Song, J.I. Lee, K.-H. Yoo. J. Appl. Phys., 96, 5496 (2004).

Редактор А.Н. Смирнов

\section{Pulsed laser irradiation of GaAs-based light-emitting structures}

O.V. Vikhrova ${ }^{1}$, Yu.A. Danilov' ${ }^{1}$, B.N. Zvonkov' ${ }^{1}$, I.L. Kalentyeva ${ }^{1}$, A.V. Nezhdanov ${ }^{2}$, A.E. Parafin ${ }^{3}$, D.V. Khomitsky ${ }^{2}$, I.N. Antonov ${ }^{1}$

${ }^{1}$ Physical Technical Research Institute of the Lobachevsky State University of Nizhny Novgorod, 603950 Nizhny Novgorod, Russia

${ }^{2}$ Lobachevsky State University of Nizhny Novgorod, 603950 Nizhny Novgorod, Russia

${ }^{3}$ Institute for Physics of Microstructures,

Russian Academy of Sciences, 603950 Nizhny Novgorod, Russia

Abstract The effects of $\mathrm{KrF}$ excimer laser pulses on the crystalline and optical properties of structures with four $\mathrm{In}_{x} \mathrm{Ga}_{1-x} \mathrm{As} / \mathrm{GaAs}$ quantum wells ( $x$ ranged from 0.08 to 0.25 ) were studied. The results obtained by Raman spectroscopy and reflection spectroscopy showed that the high crystalline quality of the GaAs cap layer is retained after exposure to laser radiation with an energy density of 200 to $360 \mathrm{~mJ} / \mathrm{cm}^{2}$. It was established experimentally by photoluminescence spectroscopy and by modeling the laser annealing process, which is a solution to the problem of heat propagation in a one-dimensional GaAs-based system, that the thermal effects that occur in heterostructures under pulsed laser irradiation below the GaAs melting threshold lead to relaxation of mechanical stresses. At the initial stages of this process, the point defects appear in $\operatorname{In}_{x} \mathrm{Ga}_{1-x} \mathrm{As} / \mathrm{GaAs}$ quantum wells. The latter lead to a „red“ shift of the photoluminescence emission peaks of quantum wells and serve as centers of nonradiative recombination, which causes the quenching of the photoluminescence. 